\title{
Symptoms in a Population of Contact Lens and Noncontact Lens Wearers Under Different Environmental Conditions
}

\author{
JOSE MANUEl GONZALEZ-MEIJOME, OD, FIACLE, MANUEL A. PARAFITA, MD, PhD, \\ EVA YEBRA-PIMENTEL, PhD, and JOSE B. ALMEIDA, PhD
}

Department of Physics (Optometry), School of Sciences, University of Minho, Braga, Portugal (JMG-M, JBA), Department of Surgery (Ophthalmology) (MAP) and Department of Applied Physics (Optometry) (EY-P), School of Optics and Optometry, University of Santiago de Compostela, Spain

\begin{abstract}
Purpose. To investigate ocular symptoms related to dryness in an adult population of contact lens (CL) and non contact lens wearers ( $\mathrm{n}-\mathrm{CL})$ using video display terminals (VDT) for different periods of time under different indoor conditions related to air conditioning (AC) and heating units (HU) exposure.

Methods. A questionnaire was distributed to 334 people within a university population of which 258 were part of the $\mathrm{n}-\mathrm{CL}$ group and 76 of the CL wearers to assess symptoms of ocular discomfort potentially related to dryness. Only soft contact lens $(S C L)$ wearers $(n=71)$ were included for further statistical analysis because of the reduced number of people wearing other lens types. A 2:1 match by gender group of 142 subjects in the $\mathrm{n}-\mathrm{CL}$ group was used as a control sample. Results. There was a marked difference between the prevalence of symptoms and the way they are reported by $C L$ and $\mathrm{n}-\mathrm{CL}$ wearers. Red eye, itching, and scratchiness are more common among CL wearers, but the difference is statistically significant only for scratchiness $\left(p<0.01, \chi^{2}\right)$. The vast majority of subjects who reported symptoms often and at the end of the day are significantly more prevalent among $C L$ wearers $\left(p<0.01, \chi^{2}\right)$. Gender differences were also encountered. Female $C L$ wearers reported more scratchiness than males in the $n-C L$ wearing group $\left(p=0.029, \chi^{2}\right)$ and in the $C L$ group $\left(p<0.008, \chi^{2}\right)$. Females wearing $C L$ reported symptoms of red eye $\left(p=0.043, \chi^{2}\right)$ and scratchiness $\left(p<0.001, \chi^{2}\right)$ more significantly than those in the $\mathrm{n}-\mathrm{CL}$ group. Within the $\mathrm{CL}$ group, the prevalence of symptoms occurring sometimes or often and at the end of the day was higher among females $\left(p<0.001, \chi^{2}\right)$. The use of VDT was associated with a higher level of scratchiness among CL wearers $\left(p<0.05, \chi^{2}\right)$. The number of hours working with VDTs seemed to be associated with an increase in the prevalence of burning sensation in the $C L$ group $\left(p<0.01, \chi^{2}\right)$, whereas symptoms like red eye and scratchiness also increased significantly among $n-C L$ wearers. Compared to $n-C L$ wearers, all symptoms increase in $C L$ wearers in environments with $\mathrm{AC}$ and $\mathrm{HU}$, except excessive tearing. However, these differences are only statistically significant for scratchiness.
\end{abstract}

Conclusions. Our results show that people who wear soft CL and work with VDTs for longer periods of time are more likely to develop symptoms like eye burning and scratchiness than $\mathrm{n}-\mathrm{CL}$ wearers. This risk could be higher for women than men. Scratchiness and the appearance of symptoms near the end of the day are typically associated with ocular discomfort during $\mathrm{CL}$ wear in this sample, and clinicians should question their patients about these symptoms to anticipate serious discomfort.

(Optom Vis Sci 2007;84:1

Key Words: adverse environment, ocular symptoms, soft CL, complaints, marginal dry eye

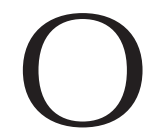
cular dryness is one of the most common complaints made to eye care professionals. It has increased considerably in recent years because of the aging of the population, tan increase in systemic drug intake, changing environmental condi- tions, and corneal refractive surgery procedures. ${ }^{1,2}$ However, treatment is often difficult because of the great variety of factors involved in its etiology, ${ }^{3,4}$ and the relatively low efficacy of current treatments in providing symptom relief., 
2 Symptoms in CL and Non CL Wearers-González-Méijome et al.

Ocular dryness affects 35 to $60 \%$ of contact lens (CL) wearers and is one of the most important causes of CL discontinuation in the medium and long terms. ${ }^{7}$ Women are more prone to suffer from dry eye and they are twice as likely to describe dryness symptoms than men. ${ }^{8}$

Pathologic dry eye seriously affects the patient's quality of life, ${ }^{9}$ and is a contraindication for cosmetic CL wear. However, even in mild cases, dryness symptoms can be very challenging for patients wearing CL. Many studies have confirmed an increase in dry eye symptoms associated with CL wear. ${ }^{10}$ Previous studies have shown that dryness symptoms in CL wearers are seriously affected by environmental parameters, ${ }^{11}$ and a recent study has confirmed that such symptoms could be driven by thinning and instability of the prelens tear film in low relative humidity and low temperature environments. ${ }^{12}$

Currently, the aging of the CL wearers in developed countries, along with the increase in the intensive use of video display terminals (VDT) and increased treatment of indoor environments could exacerbate dryness symptoms in CL wearers. The age-related systemic diseases such as rheumatoid arthritis, which are prone to exacerbate dry eye symptoms, and the use of drying medications such as diuretics and antihistaminic drugs are matters of further concern. In addition, the impact of refractive surgery procedures in tear function is well known. ${ }^{13}$ So, considering the demographic evolution, the increase in the prescription of soft contact lens (SCL) in the last 30 years, and the expansion of refractive surgery procedures in the last decade, patients wearing CL will present some of these symptoms more frequently in the future.

The aim of this study was to evaluate the prevalence of ocular symptoms among CL wearers and noncontact lens (n-CL) wearers under different environmental conditions and the use of VDT.

\section{METHODS}

This is a comparative analysis on the global report of ocular symptoms in an observational, cross-sectional study involving CL and n-CL wearers with 334 people in the academic population of the University of Minho (Braga, Portugal). The data were collected during November 2005. As patients completed the questionnaire, they gave their consent for data to be anonymously processed for this study. One hundred seventy of them were males $(50.9 \%)$ and 164 were females (49.1\%). The mean age was $25.4 \pm 7.8$ ranging from 18 to 61 years old. To homogenize the sample, five CL wearers were excluded from the sample because of they were using, or have been recently using, other types of lenses different from SCL. Thus, for statistical purposes only $71 \mathrm{CL}$ wearers $(22$ males,
49 females) and 142 n-CL wearers (44 males, 98 females) in a 2:1 match by gender control group were analyzed.

A questionnaire was completed by 334 people (see Appendix) regarding symptoms of dry eye ("red eye", "itching", "excessive tearing", "burning," and sand sensation or "scratchiness") and their frequency ("sometimes", "often", "all the time", "early in the morning," and at the "end of the day"). Despite other studies considering ocular discomfort or dryness symptoms, we chose these five symptoms as those are more specifically associated with CL-related dry eye symptoms ${ }^{14-16}$; dryness and discomfort were not questioned directly. Specific questions regarding environmental conditions at work/study place were included in order to obtain information about environmental factors that can potentially affect the prevalence of ocular symptoms. These include the use of VDT, type of VDT (cathode ray tube, CRT or thin film transistor, TFT), their average daily use in hours, and the use of heating units (HU) and air conditioning (AC) units at work/study place.

The statistical analysis was carried out with SPSS v14.0. Descriptive statistics were obtained to characterize the sample, the CL wear profile, and the prevalence of symptoms. To compare symptoms among CL and n-CL wearers or those under the environmental conditions quoted above, the Pearson $\chi^{2}$ test was used. ${ }^{17}$ Restrictions applied to this test include $<20$ elements involved in the comparison, all groups compared had more than one element, and at least $80 \%$ of the groups had more than five elements. The level of statistical significance was established for $\propto=0.05$, although other degrees of significance are also identified in tables and graphics throughout the text.

\section{RESULTS}

The distribution between CL and n-CL wearers was 33.3\% and $66.7 \%$, respectively. Only SCL wearers were considered for subsequent analysis. Demographic data regarding the patients actually included in the statistical analysis are listed in Table 1. All subjects T1 in the CL group declared they used their lenses daily. In the group of CL wearers, $28.2 \%$ were using or had used artificial tears because of complaints, whereas only $3.5 \%$ described this fact in the $n-C L$ wearing group.

\section{Symptoms Among CL and $\mathrm{n}-\mathrm{CL}$ Wearers}

Fig. 1 presents the prevalence of different symptoms in both $\mathbf{F} 1$ groups. CL wearers present a higher prevalence of symptoms of red eye, itching and scratchiness, being statistically significant for red eye $\left(p=0.009, \chi^{2}\right)$, and scratchiness $\left.p<0.001, \chi^{2}\right)$. The opposite

\section{TABLE 1.}

Demographic data for CL and $\mathrm{n}-\mathrm{CL}$ wear groups

\begin{tabular}{lrr}
\hline & n-CL group & $C$ group $^{\mathrm{a}}$ \\
\hline Sample size, $\mathrm{n}(\%)$ & $142(67.7)$ & $71(33.3)$ \\
Male:female ratio, $\mathrm{n}(\%)$ & $44: 98(31: 69)$ & $22: 49(31: 69)$ \\
Age, mean \pm SD (range) & $23.65 \pm 5.12(18-47)$ & $24.9 \pm 5.47(19-38)$ \\
Wearing time (yr), mean \pm SD (range) & - & $4.93 \pm 4.76(0.1-25)$ \\
\hline
\end{tabular}

${ }^{\mathrm{a} O n l y}$ soft $\mathrm{CL}$ wearers were considered. 
Symptoms in CL and Non CL Wearers-González-Méijome et al. 3

\section{Symptoms}

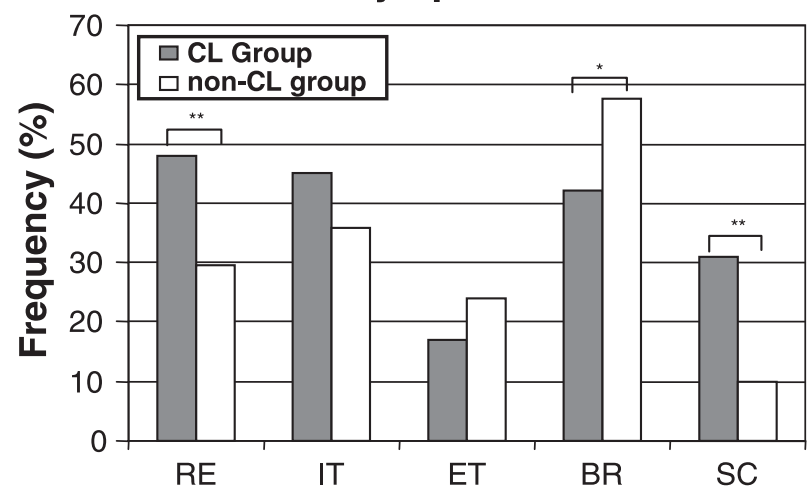

FIGURE 1.

Frequency of symptoms of red eye (RE), itching (IT), excessive tearing (ET), burning (BR), and scratchiness (SC) for subjects in the CL wear group (dark bars) and $\mathrm{n}-\mathrm{CL}$ group (white bars). Brackets indicate significant differences $\left({ }^{*} p<0.05 ;{ }^{* *} p<0.01\right)$.

\section{Symptoms}

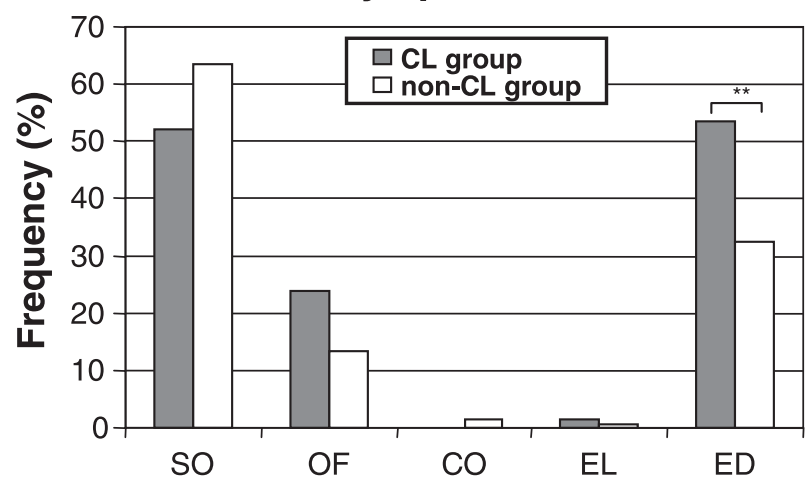

FIGURE 2.

Pattern of symptom appearance as being "sometimes" (SO), "often" (OF), "constant" (CO), "early in the day" (EL), and at the "end of the day" (ED) in the $\mathrm{CL}$ and $\mathrm{n}-\mathrm{CL}$ wear groups. Brackets indicate significant differences $\left({ }^{*} \mathrm{p}<0.05 ;{ }^{* *} \mathrm{p}<0.01\right) . \chi^{2}$ not applicable at $\mathrm{CO}$ and $\mathrm{EL}$, because more than $20 \%$ of the samples have expected count $<5$.

trend was found for burning sensation $\left(p=0.033, \chi^{2}\right)$. Fig. 2 presents the frequency of those symptoms (sometimes, often, constantly) and their pattern of appearance (early in the day, end of the day). Almost no subject in either group presented symptoms "constantly" or "early in the day." However, the proportion of CL wearers reporting the symptoms "often" is higher than that of the $\mathrm{n}$-CL group $\left(\mathrm{p}=0.052, \chi^{2}\right)$ and the symptoms are more likely to be noticed at the "end of the day" in the CL group $\left(p<0.001, \chi^{2}\right)$. The presence of occasional symptoms as described "sometimes" by the patients does not per se imply contact lens-related dry eye because its incidence is even higher in the $\mathrm{n}$-CL wearing group than in the CL group $\left(\mathrm{p}=0.142, \chi^{2}\right)$.

\section{Symptoms Among Male and Female CL and n-CL Wearers}

Table 2 shows the prevalence of symptoms for male and female subjects. The prevalence of burning sensation was significantly higher among females in the $\mathrm{n}-\mathrm{CL}$ group $\left(\mathrm{p}=0.019, \chi^{2}\right)$, whereas females wearing CL reported a significantly higher prevalence of

\section{TABLE 2.}

Prevalence of symptoms as a function of gender for $\mathrm{CL}$ and $\mathrm{n}-\mathrm{CL}$ wear groups

\begin{tabular}{|c|c|c|c|c|}
\hline & \multicolumn{2}{|c|}{$\mathrm{n}-\mathrm{CL}$ group $(\mathrm{n}=142)$} & \multicolumn{2}{|c|}{$C L$ group $(n=71)$} \\
\hline & Cases $(\%)$ & $\chi^{2}$ (sig. p) & Cases (\%) & $\chi^{2}$ (sig. p) \\
\hline Red eye & & 0.402 & & 0.811 \\
\hline Male & $11(25)$ & & $11(50)$ & \\
\hline Female & $31(32)$ & & $23(47)$ & \\
\hline Itching & & $0.069^{\mathrm{a}}$ & & 0.637 \\
\hline Male & $11(25)$ & & $9(41)$ & \\
\hline Female & $40(41)$ & & $13(47)$ & \\
\hline $\begin{array}{l}\text { Excessive } \\
\text { tearing }\end{array}$ & & 0.820 & & $-^{\mathrm{b}}$ \\
\hline Male & $10(23)$ & & $2(9)$ & \\
\hline Female & $24(24)$ & & $10(21)$ & \\
\hline Burning & & $0.019^{c}$ & & 0.714 \\
\hline Male & $19(43)$ & & $10(46)$ & \\
\hline Female & $63(64)$ & & $20(41)$ & \\
\hline Scratchiness & & 0.415 & & $0.008^{\mathrm{d}}$ \\
\hline Male & $3(7)$ & & $2(9)$ & \\
\hline Female & $11(11)$ & & $20(41)$ & \\
\hline
\end{tabular}

aStatistically significant at 0.1 level.

${ }^{\mathrm{b}} \chi^{2}$ Test not applicable because more than $20 \%$ have expected count $<5$ for some group.

cStatistically significant at 0.05 level.

${ }^{\mathrm{d}}$ Statistically significant at 0.01 level.

\section{TABLE 3.}

Frequency of symptoms between males and females for $\mathrm{CL}$ and $\mathrm{n}-\mathrm{CL}$ groups

\begin{tabular}{|c|c|c|c|c|}
\hline & \multicolumn{2}{|c|}{$\mathrm{n}-\mathrm{CL}$ group $(\mathrm{n}=142)$} & \multicolumn{2}{|c|}{$C L$ group $(n=71)$} \\
\hline & Cases (\%) & $\chi^{2}$ (sig. p) & Cases $(\%)$ & $\chi^{2}$ (sig. p) \\
\hline Sometimes & & 0.675 & & 0.193 \\
\hline Male & $29(66)$ & & $14(64)$ & \\
\hline Female & $61(62)$ & & $23(47)$ & \\
\hline Often & & $0.038^{a}$ & & $0.049^{a}$ \\
\hline Male & $2(5)$ & & $2(9)$ & \\
\hline Female & $17(17)$ & & $15(31)$ & \\
\hline All the time & & $-\mathrm{b}$ & & $-^{b}$ \\
\hline Male & $0(0)$ & & $0(0)$ & \\
\hline Female & $2(2)$ & & $0(0)$ & \\
\hline Early in the day & & $-\mathrm{b}$ & & $\underline{b}^{\mathrm{b}}$ \\
\hline Male & $1(2)$ & & $0(0)$ & \\
\hline Female & $0(0)$ & & $1(2)$ & \\
\hline End of the day & & $0.001^{\mathrm{c}}$ & & 0.361 \\
\hline Male & $6(14)$ & & $10(45)$ & \\
\hline Female & $40(41)$ & & $28(57)$ & \\
\hline
\end{tabular}

a Statistically significant at 0.05 level.

${ }^{\mathrm{b}} \chi^{2}$ Test not applicable because more than $20 \%$ have expected count $<5$ for some group.

'Statistically significant at 0.01 level.

dStatistically significant at 0.1 level.

scratchiness $\left(\mathrm{p}<=0.008, \chi^{2}\right)$ than males. Table 3 shows the T3 pattern of appearance of symptoms for males and females in the CL and n-CL groups. Females are more likely to present symptoms AQ: 1 "often" than males in the n-CL and CL groups $\left(p<0.05, \chi^{2}\right)$. 


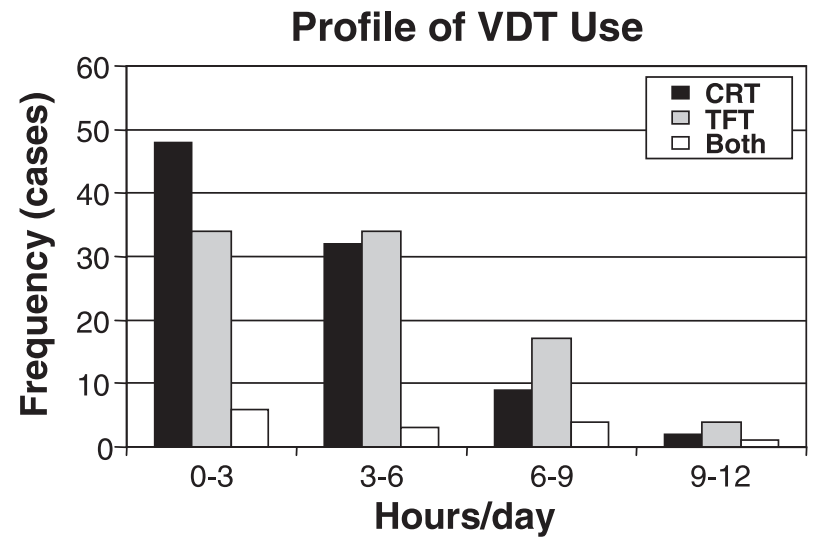

FIGURE 3.

Use (h/day) for different VDT.

However in the CL group, females reported more frequently again that they felt the symptoms "often" $\left(p=0.049, \chi^{2}\right)$.

\section{Symptoms Among CL and n-CL Wearers and VDT}

Daily use of VDT was reported by $98.5 \%$ of people answering the questionnaire. Of those included in the statistical analysis, 49.5\% use CRT displays, $43.8 \%$ use TFT displays, and $6.7 \%$ use both of them, with different daily exposure profiles as observed in Fig. 3. When compared with CRT, the proportion of people using TFT displays increases as the number of hours of daily use increases. Although the number of CRT displays is higher for those using them for $<3 \mathrm{~h} /$ day, TFT displays are more frequent for those using them more than $3 \mathrm{~h} /$ day, particularly for the more intensive users $(>6 \mathrm{~h} /$ day).

Figures $4 \mathrm{a}$ and $4 \mathrm{~b}$ depict the pattern of symptoms presentation in $\mathrm{CL}$ and $\mathrm{n}$-CL wear groups as a function of the daily exposure to VDTs. Comparative prevalence of symptoms among different VDTs users showed that scratchiness was significantly more frequent in CL wearers using both types of terminals for more than $3 \mathrm{~h}$.

In the n-CL group, the symptoms were more prevalent as the number of hours spent working with computers increased. Those trends were statistically significant for "itching", "excessive tearing," and "scratchiness." On the other hand, in the CL group, the prevalence of symptoms increased in subjects using VDT 3 to $6 \mathrm{~h}$ a day, but not in the group using VDTs 6 to $9 \mathrm{~h}$ a day. For those CL wearers using VDTs for $<3 \mathrm{~h}$ a day the "burning" sensation was significantly lower than for those using them for 3 to $6 \mathrm{~h}(\mathrm{p}=$ $0.016, \chi^{2}$ ) and for those CL wearers using VDTs 3 to $6 \mathrm{~h}$ a day "scratchiness" was significantly higher $\left(p=0.048, \chi^{2}\right)$.

In general, the number of hours using VDTs did not affect the pattern of appearance of the symptoms, except for the response "end of the day" that presented statistically significant differences with increasing hours for $n-C L$ group $\left(p=0.017, \chi^{2}\right)$. For those using VDTs for 3 to $6 \mathrm{~h}$ a day, the percentage of patients reporting symptoms at the "end of day" was significantly higher in the CL group $\left(p=0.006, \chi^{2}\right)$. This behavior was also observed for those CL wearers using VDTs for 6 to $9 \mathrm{~h}$ a day $\left(\mathrm{p}=0.002, \chi^{2}\right)$.

Overall, the prevalence of most symptoms is more frequent in CL than n-CL wearers as seen in Figures $4 \mathrm{a}$ and $4 \mathrm{~b}$. A statistical comparison between n-CL and CL wearers has showed that "red
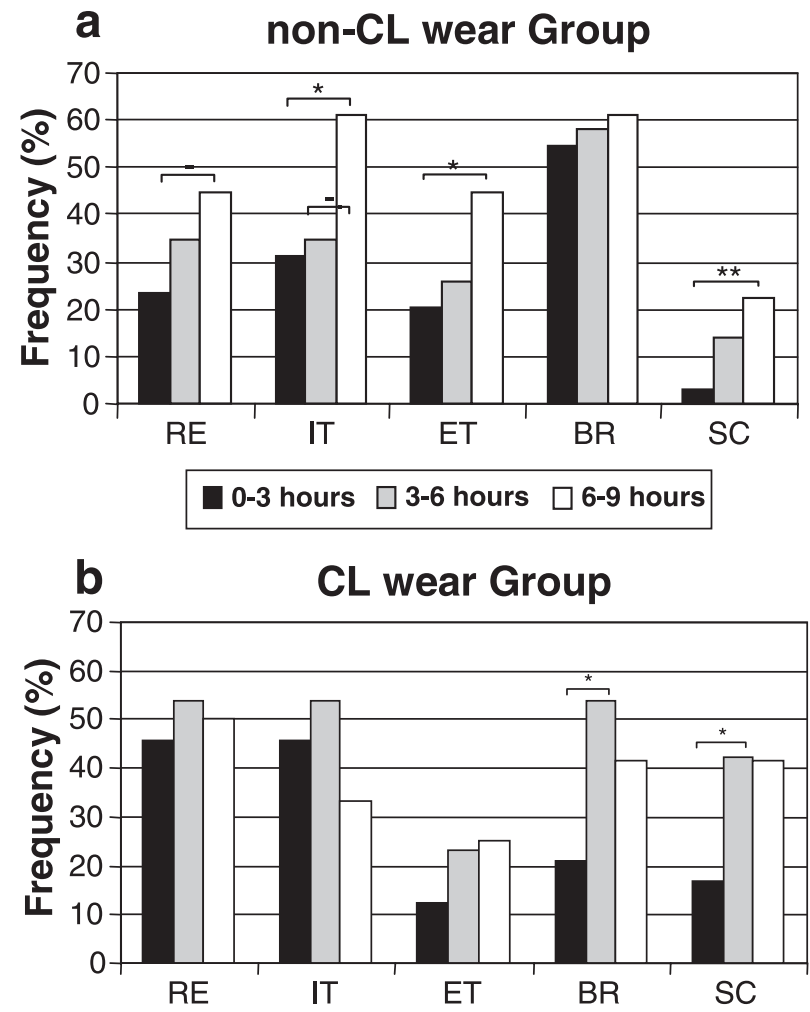

FIGURE 4.

Frequency of symptoms of red eye (RE), itching (IT), excessive tearing (ET), burning (BR), and scratchiness (SC) as a function of the number of hours a day using VDT in the $\mathrm{n}-\mathrm{CL}$ group (a) and CL wear group (b). Brackets indicate significant differences (- for $p<0.1$, ${ }^{*} p<0.05$; ${ }^{* *} p<0.01$ ).

eye" $\left(\mathrm{p}=0.040, \chi^{2}\right)$ and "burning sensation" $\left(\mathrm{p}=0.005, \chi^{2}\right)$ are significantly more frequent in $\mathrm{CL}$ wearers than $\mathrm{n}-\mathrm{CL}$ wearers using VDTs $<3 \mathrm{~h} /$ day; for those using VDTs 3 to $6 \mathrm{~h} /$ day scratchiness was significantly more prevalent in CL than $\mathrm{n}-\mathrm{CL}$ wearers $(\mathrm{p}=$ $\left.0.008, \chi^{2}\right)$.

\section{Symptoms Among CL and n-CL Wearers and Indoor Environment Conditions (AC and HU)}

Among those working/studying in $\mathrm{AC}$ and $\mathrm{HU}$ environments, the prevalence of symptoms increased in CL wearers compared to n-CL wearers except for the burning sensation (Fig. 5). Scratchi- F5 ness was the only symptom with a significantly higher prevalence among CL than $\mathrm{n}-\mathrm{CL}$ wearers using $\mathrm{AC}\left(\mathrm{p}<0.006, \chi^{2}\right)$ and HU $\left(\mathrm{p}<0.005, \chi^{2}\right)$.

\section{DISCUSSION}

Ocular dryness and related symptoms continue to be the main complaint among CL wearers and it is believed that this is why CL wearers discontinue their use ${ }^{18}$ and opt for other vision correction strategies such as refractive surgery. ${ }^{19}$ Discomfort was indicated as the main reason by $51 \%$ of patients that discontinued CL wear in the UK. ${ }^{7}$

In this study, we have identified a higher prevalence of certain symptoms potentially associated with changes to the ocular surface in the CL wear population. Those who "often" reported symptoms increased significantly in the CL wearing group (24\%) compared 

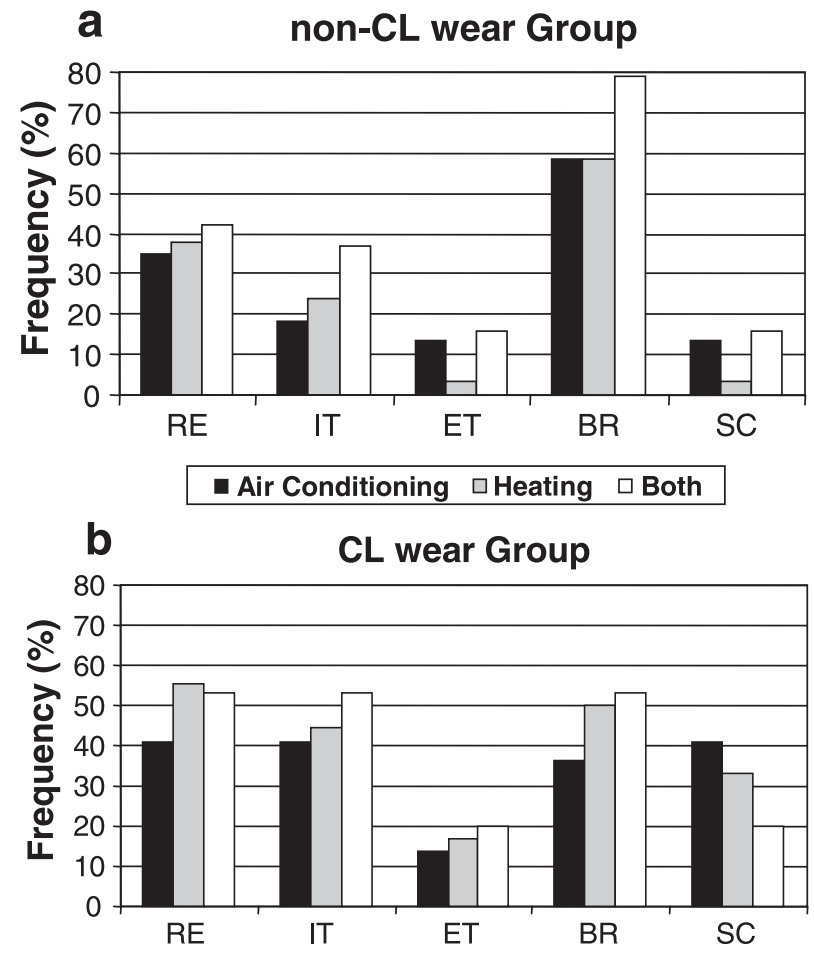

FIGURE 5.

Frequency of symptoms of red eye (RE), itching (IT), excessive tearing (ET), burning (BR), and scratchiness (SC) for subjects using $A C$, heating devices or both in the $\mathrm{n}-\mathrm{CL}$ group (a) and $\mathrm{CL}$ wear group (b).

to $\mathrm{n}$-CL wearers $(13 \%)$. This is consistent with the results presented by Fonn et al., who described an almost linear decrease in patient comfort with different types of hydrogel and silicone hydrogel CL during a 7-h period among a group of symptomatic CL wearers. ${ }^{20}$ The level of scratchiness was the most significant difference between $\mathrm{CL}$ and $\mathrm{n}-\mathrm{CL}$ wearers. Also, symptoms are more likely reported at the end of the day; $53.5 \%$ of $C L$ wearers reported symptoms later in the day, whereas only $32 \%$ of $n-C L$ wearers reported this.

The main reasons for the presence of these symptoms may be found in the tear stability, or lack of it, over the CL material, which can be adversely affected by environmental conditions of air temperature (AT) and relative humidity (RH) ${ }^{21-23}$ It is generally accepted that prelens tear stability is significantly affected by low humidity environments. In a recent study, Maruyama et al. ${ }^{12}$ have concluded that no statistically significant differences in tear volume was detected under different AT $\left(10\right.$ to $\left.35^{\circ}\right)$ and $\mathrm{RH}$ (10 to $50 \%$ ) conditions. However, they found that although noninvasive tear break-up time was independent of the environmental conditions without a CL in place, it decreased significantly as the air became dryer and colder for high and low water content SCL. These findings were associated with an increase of dryness complaints, particularly in high water content SCL. ${ }^{12}$ Nichols et al. have recently described similarities between the thinning of the prelens and precorneal tear film involving evaporation, dewetting, and pressure-gradient flows. ${ }^{24}$ However, the thinning process was more rapid over the CL material and the authors related more rapid thinning to dewetting processes. This could explain the higher prevalence of symptoms among CL wearers, particularly at the end of the day when the CL surface wettability could be more seriously affected.

For the population in this study, the use of heating devices in the work place might enhance ocular symptoms, which was not the case for those using air conditioner units that seemed to present a weaker correlation with the raising of ocular symptoms.

We noticed that working with VDTs can also influence the frequency of symptoms, particularly for those using TFT displays. However, this was probably related to a more intensive use of these displays rather than to the nature of the VDT. Indeed, for this population, the daily use of VDT was significantly higher than that reported by Begley et al. for the general population. ${ }^{2}$ Working with computers is a relevant matter of concern when fitting SCL to patients with the VDT exposure pattern reported in the present study. The fact that the most intensive VDT users do not present any severe symptoms suggests that a limited number of hours (perhaps between 3 and $6 \mathrm{~h}$ of computer use) might become irritating for CL wearers, and that above that number there is no increased impact on the wearer. However, more specific studies should be carried out to confirm this hypothesis.

The proportion of $C L$ wearers reporting symptoms at the end of the day is almost twice as large for those in the n-CL group. In a recent study, Begley et al. have shown that for all symptoms under study, Sjögren's syndrome (SS) and non-Sjögren's syndrome keratoconjunctivitis sicca (non-SS KCS) groups presented an increase in the number of subjects who reported moderate to aggravated symptoms in the evening. For example, $67 \%$ of subjects with SS and $32 \%$ of subjects with non-SS KCS reported moderate to severe discomfort in the morning vs. $90 \%$ in the SS group and $60 \%$ in the non-SS KCS group in the evening. ${ }^{17}$ In the present study, almost no subject reported symptoms early in the day. This suggests that the pattern of appearance of symptoms (morning vs. evening) could be important to differentiate between pathological and marginal CL-related symptoms.

Furthermore, a recent study has shown that clinicians often underestimate the severity of dry eye conditions, particularly as far as older women are concerned. ${ }^{1,25}$ In the authors' opinion although it is not possible to evaluate a general population directly, this suggests that CL wearers are at risk of developing symptoms who cannot be correctly managed might face a risk of CL intolerance in the future, if the clinicians rely only on clinical signs of dry eye to change the fitting/wearing strategy. However, to date, no standard tool has been provided for a proper subjective evaluation of CL related symptoms. Meanwhile, direct questions must be asked to patients wearing CL about their eye sensations and the way that these present themselves. Scratchiness at the end of the day appears to be key points to detect subtle problems in an early stage. This fits with the conclusions drawn in a recent study. ${ }^{14}$ Our study shows that this is even more important for females, for intensive VDT users, and for subjects who work in indoor heated environments. Strategies such as more frequent lens replacement, more intense cleaning, and a reduced wear schedule should be adopted earlier to maintain comfortable and safe CL wear.

In general terms, our results suggest that those CL wearers, (particularly young women) that use of VDT for long hours in air conditioned rooms, run a higher risk of presenting certain symptoms (mainly scratchiness) at the end of the day. If not solved, such a condition could lead to the discontinuation of CL wear in the 
6 Symptoms in CL and Non CL Wearers-González-Méijome et al.

medium term. The "at risk" group corresponds to the prototype of the most common contact lens wearers in Portugal to be fitted for the first time or refitted. Within this specific populations, $66.5 \%$ are female and aged $28 \pm 10$ (whole sample); $20 \%$ of the patients who are refitted describe frequent symptoms vs. $10 \%$ of first fits, and $30 \%$ describe symptoms in the evening against $16 \%$ in the first fitting group. These differences are statistically significant at $\mathrm{p}=$ 0.05 and $\mathrm{p}=0.01$ levels, respectively. ${ }^{26}$

\section{CONCLUSIONS}

Current demographic and socioeconomic trends along with the current CL wearer profile could lead to an increasing proportion of CL-related symptoms among the world population of CL wearers. Despite significant improvements in CL materials and palliative treatments that could reduce these problems in the future, clinicians should consider new standards of subjective evaluation. This includes the prefitting investigation of risk factors that can potentially affect $\mathrm{CL}$ tolerance in the medium and long terms, and a proper follow-up schedule with direct questions that allow early detection of symptoms that can suggest changes in the CL wearing strategy.

\section{ACKNOWLEDGEMENTS}

This study was partially supported by a grant from the Science and Technology Foundation (FCT) - Ministry of Science and Superior Education (MCES) under contract 8281/2002 from the European Social Funding granted to JMG-M.

None of the authors has a commercial or financial interest in the instruments or materials used in the study.

The authors wish to thank the assistance of AP Almeida, AP Costa, A Fernandes, A Teixeira, C Marques, C Pinho and J Matos for their assistance in data acquisition, and Dr. Ana Costa from the program of Support to the Edition of Scientific Papers at the University of Minho for help with English editing of the manuscript.

Received May 10, 2006; accepted September 15, 2006.

\section{APPENDIX}

The appendix is available online at http://www.optvissci.com.

\section{REFERENCES}

1. Schaumberg DA, Sullivan DA, Buring JE, Dana MR. Prevalence of dry eye syndrome among US women. Am J Ophthalmol 2003;136:318-26.

2. Begley CG, Chalmers RL, Mitchell GL, Nichols KK, Caffery B, Simpson T, DuToit R, Portello J, Davis L. Characterization of ocular surface symptoms from optometric practices in North America. Cornea 2001;20:610-18.

3. Dogru M, Stern ME, Smith JA, Foulks GN, Lemp MA, Tsubota K. Changing trends in the definition and diagnosis of dry eyes. Am J Ophthalmol 2005;140:507-18.

4. Foulks GN. What is dry eye and what does it mean to the contact lens wearer? Eye Contact Lens 2003;29:S96-S100.

5. Albietz JM. Dry eye: an update on clinical diagnosis, management and promising new treatments. Clin Exp Optom 2001;84:4-18.

6. Shimmura S, Shimazaki J, Tsubota K. Results of a population-based questionnaire on the symptoms and lifestyles associated with dry eye. Cornea 1999;18:408-11.

7. Young G, Veys J, Pritchard N, Coleman S. A multi-centre study of lapsed contact lens wearers. Ophthalmic Physiol Opt 2002;22: 516-27.

8. McCarty CA, Bansal AK, Livingston PM, Stanislavsky YL, Taylor
HR. The epidemiology of dry eye in Melbourne, Australia. Ophthalmology 1998;105:1114-19.

9. Mertzanis P, Abetz L, Rajagopalan K, Espindle D, Chalmers R, Snyder C, Caffery B, Edrington T, Simpson T, Nelson JD, Begley C. The relative burden of dry eye in patients' lives: comparisons to a U.S. normative sample. Invest Ophthalmol Vis Sci 2005;46:46-50.

10. Nichols JJ, Ziegler C, Mitchell GL, Nichols KK. Self-reported dry eye disease across refractive modalities. Invest Ophthalmol Vis Sci 2005; 46:1911-14.

11. Nilsson SE, Andersson L. Contact lens wear in dry environments. Acta Ophthalmol (Copenh) 1986;64:221-5.

12. Maruyama K, Yokoi N, Takamata A, Kinoshita S. Effect of environmental conditions on tear dynamics in soft contact lens wearers. Invest Ophthalmol Vis Sci 2004; 45:2563-8.

13. De Paiva CS, Chen Z, Koch DD, Hamill MB, Manuel FK, Hassan SS, Wilhelmus KR, Pflugfelder SC. The incidence and risk factors for developing dry eye after myopic LASIK. Am J Ophthalmol 2006; 141:438-45.

14. Guillon M, Maissa C. Dry eye symptomatology of soft contact lens wearers and nonwearers. Optom Vis Sci 2005;82:829-34.

15. Pritchard N, Fonn D, Brazeau D. Discontinuation of contact lens wear: a survey. Int Contact Lens Clin 1999;26:157-62.

16. Brennan NA, Efron N. Symptomatology of HEMA contact lens wear. Optom Vis Sci 1989;66:834-8.

17. Begley CG, Chalmers RL, Abetz L, Venkataraman K, Mertzanis P, Caffery BA, Snyder C, Edrington T, Nelson D, Simpson T. The relationship between habitual patient-reported symptoms and clinical signs among patients with dry eye of varying severity. Invest Ophthalmol Vis Sci 2003;44:4753-61.

18. Young G. Why one million contact lens wearers dropped out. Cont Lens Anterior Eye 2004;27:83-5.

19. Naroo SA, Shah S, Kapoor R. Factors that influence patient choice of contact lens or photorefractive keratectomy. J Refract Surg 1999;15: 132-6.

20. Fonn D, Dumbleton K. Dryness and discomfort with silicone hydrogel contact lenses. Eye Contact Lens 2003;29:S101-S104.

21. Refojo MF. Tear evaporation considerations and contact lens wear. In: Flattau PE, ed. Considerations in Contact Lens Use Under Adverse Conditions. Proceedings of a Symposium. Washington, DC: National Academy Press; 1991:38-43.

22. Refojo MF. The tear film and contact lenses: the effect of water evaporation from the ocular surface. In: Calabria G, Rolando M, eds. Fisiopatologia Del Film Lacrimale. Rome: Società Oftalmologica Italiana; 1984:189-97.

23. Refojo MF. [Environmental conditions and tolerance of contact lenses.] Rev Esp Contact 2004;11:3-4.

24. Nichols JJ, Mitchell GL, King-Smith PE. Thinning rate of the precorneal and prelens tear films. Invest Ophthalmol Vis Sci 2005;46: 2353-61.

25. Chalmers RL, Begley CG, Edrington T, Caffery B, Nelson D, Snyder $\mathrm{C}$, Simpson T. The agreement between self-assessment and clinician assessment of dry eye severity. Cornea 2005;24:804-10.

26. Gonzalez-Meijome JM, Jorge J, Almeida JB, Parafita MA. Trends in contact lens fitting profile in Portugal 2005: strategies for first fit and re-fitted patients. Eye Contact Lens, in press.

José Manuel González-Méijome Department of Physics (Optometry) Campus de Gualtar, University of Minho 4710-057 Braga, Portugal e-mail: jgmeijome@fisica.uminho.pt 


\section{APPENDIX}

Please, answer the following questions placing $\bigotimes$ where appropriate.

\section{Preliminary Data}

- Male $\square$ Female $\square$ Age $\square$ Occupation $\square$

- Do you wear contact lenses?

No, I do not wear contact lenses

Yes $\square$ Soft/Hydrogel $\square$ Rigid and Rigid Gas Permeable $\square$ For how

long? $\square$ years/months

\section{Questionnaire}

1. Have you ever used drops for your eyes?

No $\square$ Yes $\square$ Which kind: Drugs $\square$ Artificial Tears/Saline

2. Which kind of symptoms/signs did you feel after a normal day working/studying?

Red eye $\square$ Itching $\square$ Excessive tearing $\square$ Scratchiness $\square$ Burning $\square$

\section{How frequently you feel this/these} $\operatorname{sign}(\mathrm{s}) / \operatorname{symptom}(\mathrm{s})$ ?

Never $\square$ Sometimes $\square$ Frequently $\square$ Constantly $\square$

There is a specific part of the day when you feel them more? Early in the day $\square$ End of the day
4. Do you use to work/study in closed rooms with some of the following environments?

Air conditioned $\square$ Heating units $\square$ Dust $\square$ Chemicals $\square$

5. Do you use frequently computers at your working/studying place?

Yes $\square$ No $\square$

6. Do you feel some irritation after having using a computer for a prolonged period?

Yes $\square$ No $\square$ I do not use computers

\section{Which kind of screen use your computer?}

Conventional (CRT or TV-like) $\square$ Flat screen (TFT, LCD or laptop-like)

Note. This questionnaire is anonymous. By answering this questionnaire you agree that this data would be used with scientific and teaching purposes by staff of the Department of Optometry at the University of Minho.

Signature 


\section{AUTHOR QUERIES}

\section{AUTHOR PLEASE ANSWER ALL QUERIES}

1-Please indicate where the footnote ${ }^{\mathrm{d}}$ should be placed in Table 3.

2-Because there were multiple duplicate references (orig. $12 \& 25,17 \& 28,7 \& 20,2 \& 27$ ) the duplicates have been deleted and the remaining have been renumbered. Please check throughout.

3-Kindly update this reference (if possible). 